\title{
PRT-La Verdad y el movimiento estudiantil argentino. Hacia un análisis de las estrategias de inserción y de las tensiones existentes (1968-1972)
}

\section{PRT-La Verdad and the argentine student movement. Toward to the analysis of the strategies of insertion and tensions (1968-1972)}

Martín Mangiantini

\section{Resumen}

Este artículo se propone analizar la relación entre la construcción del partido PRT - La Verdad, surgido en Argentina en 1968 como resultado de una ruptura preexistente y su política de inserción en el movimiento estudiantil. Se pretende abordar la caracterización que esta corriente esgrimió del estudiantado y su importancia para la estrategia revolucionaria, las estrategias de inserción de la militancia partidaria en este actor y las tensiones existentes dentro de este partido surgidas alrededor de esta temática.

Palabras claves: trotskismo - izquierda partidaria - movimiento estudiantil - Argentina

\begin{abstract}
This paper attempts to analyze the relationship between the building party PRT - "La Verdad", emerged in Argentina in 1968 as a result of a pre-existing rupture and policy insertion in the student movement. Characterize this current students as outlined on the subject and its importance for revolutionary strategy, strategies for insertion of party membership in this actor and tensions within the party emerged around this issue will be addressed.
\end{abstract}

Keywords: trotskyism - left party - student movement - Argentina

Argentino. Profesor y Magister en Historia, docente de la UBA y del ISP Joaquín V. González. E mail: martinmangiantini@gmail.com 
El presente artículo inserta su problemática en la coyuntura política argentina acaecida entre los años 1968 y 1972, una etapa marcada por la presencia del gobierno dictatorial iniciado en 1966 y su posterior proceso de transición hacia el retorno democrático. El golpe de Estado que dio inicio a la autodenominada "Revolución Argentina" marcó un quiebre con relación a los gobiernos militares anteriormente acaecidos. Además de la extrema represión ejercida contra la oposición política, los virajes económicos experimentados con objetivos de disciplinamiento de la clase obrera y racionalización empresarial, este gobierno dinamizó una política educativa y cultural a través de la intervención de las universidades nacionales caracterizadas como focos de infiltración marxista. La resistencia docente - estudiantil desembocó en la ocupación de la Universidad de Buenos Aires (UBA) y en una brutal represión a este sector conocida como La noche de los bastones largos que generó una posterior fuga de cerebros del país. Paralelamente, se intentaron modificar las pautas de conductas sociales combatiendo aquellos rasgos considerados inmorales y ajenos a un modo de vida "occidental y cristiano".

Luego de años de derrotas para el movimiento de masas tras la realización de este golpe, el estallido del denominado Cordobazo, en mayo de 1969, significó un quiebre en la historia argentina. La derogación del denominado "sábado inglés", que otorgaba a los trabajadores de la provincia de Córdoba el pago de una jornada completa los días sábados en vez de la jornada real que era de cuatro horas fue uno de los detonantes centrales de este estallido. Estas movilizaciones obreras, a su vez, coincidieron con la agitación estudiantil en todo el país por el cierre de los comedores estudiantiles cuyas protestas derivaron en la muerte de algunos manifestantes a partir de la represión ejercida por el Estado. La movilización se transformó en una insurrección popular que terminó con el retiro transitorio de la policía tras haber agotado las municiones de balas de plomo y gases lacrimógenos.

Tras la concreción del Cordobazo, se experimentó un ascenso significativo de la militancia revolucionaria que involucró a una notable heterogeneidad de actores. Organizaciones revolucionarias que se pensaron a sí mismas como estructuras al mismo tiempo políticas y militares y que, ideológicamente, poseían un bagaje marxista, o bien, propias de un peronismo que intentaba conjugar su ideario con el paradigma socialista; un sindicalismo denominado clasista que adoptó metodologías propias de la democracia obrera para la toma de decisiones y se acercaron programáticamente a las organizaciones revolucionarias; movimientos culturales, colectivos intelectuales y hasta corrientes religiosas tales como, por ejemplo, la teología de la liberación, coexistieron en una etapa histórica marcada por la intensa participación política y la radicalización ideológica.

$\mathrm{Al}$ mismo tiempo, se dio inicio a un período atravesado por una escalada de acciones que jaquearon al orden político - social existente dando origen a una crisis orgánica que sería frenada, finalmente, con la violencia estatal llevada a su grado más extremo a partir del golpe cívico - militar de 1976. Como parte de este abanico de actores político-sociales, se destacó el movimiento estudiantil universitario y secundario, protagonista también de fundamentales luchas y clara expresión del proceso de radicalización ideológica experimentado. Este sector, notoriamente influido por un contexto mundial que tenía a la juventud como protagonista de diversas movilizaciones de masas que pugnaban por la transformación radical de la sociedad, 
Martín Mangiantini, PRT-La Verdad y el movimiento estudiantil argentino. Hacia un análisis de las estrategias de inserción y de las tensiones existentes (1968-1972) / PRT-La Verdad and the argentine student movement. Toward to the analysis of the strategies of insertion and tensions (1968-1972), Revista Izquierdas, $\mathbf{N}^{\circ} 23$, abril 2015, ISSN 0718-5049, IDEA-USACH, pp. 81-101

fue atravesado por el debate político de época y por la dicotomía entre las vertientes reformistas y revolucionarias existentes a nivel mundial. En este marco, en Argentina, la "vanguardia estudiantil” comenzó a virar paulatinamente hacia posiciones radicalizadas.

Al mismo tiempo, desde mediados de la década de 1960 se experimentó el nacimiento de un considerable número de organizaciones revolucionarias posicionadas a la izquierda del socialismo y comunismo vernáculo. La aparición de estructuras como Vanguardia Comunista (autodenominada “marxista-leninista"), el Partido Comunista Revolucionario (de orientación maoísta), Política Obrera (de extracción trotskista) como así también la formación de los incipientes grupos armados peronistas y guevaristas (tales como las Fuerzas Armadas Revolucionarias, las Fuerzas Argentinas de Liberación, las Fuerzas Armadas Peronistas y Montoneros, entre otros) fueron algunas expresiones de este fenómeno. Como parte de este abanico de agrupamientos se destacó también la presencia del Partido Revolucionario de los Trabajadores (en adelante, PRT), organización que operó unificada entre los años 1965 y 1968. En ese último año experimentó un proceso de diferenciación interna que desembocó en la ruptura de la organización en dos estructuras diversas. Por un lado, el PRT - El Combatiente (liderado por Mario Roberto Santucho, entre otros dirigentes), que luego derivó en el PRT - ERP y, por otro, el PRT - La Verdad (en adelante, PRT - LV), bajo la dirección de Nahuel Moreno. Si bien esta ruptura estuvo determinada por diversas tensiones preexistentes en el seno de su dirección, su principal motivación recayó en el debate acaecido en torno al tipo de partido político a construir, en las metodologías de inserción de tal organización entre los sectores trabajadores y, principalmente, en la viabilidad estratégica de la utilización de la lucha armada en el contexto argentino por entonces vigente ${ }^{2}$.

El objetivo del presente trabajo es analizar al PRT - LV, a partir del momento de la ruptura antes descripta, específicamente en lo pertinente a su experiencia de inserción en el movimiento estudiantil durante los siguientes cuatro años, en el marco de un período fundamental en la historia social y política argentina. Se considera que su abordaje posibilita una mejor comprensión de la convulsionada coyuntura de finales de los años sesenta y principios de los setenta y de la relación existente, en este contexto, entre una juventud radicalizada y las organizaciones revolucionarias que habitaban en su seno.

El PRT - LV fue la organización continuadora a finales de los sesenta de una de las principales corrientes trotskistas argentinas existente desde la década del cuarenta. Encabezada por Nahuel Moreno, surgió con la creación del Grupo Obrero Marxista, impulsado por un puñado de jóvenes que buscaron una inserción política en la clase obrera porteña y del Gran Buenos Aires durante el surgimiento del peronismo. Tras una cierta expansión, el grupo se convirtió en Partido Obrero Revolucionario para, posteriormente, integrarse al Partido Socialista de la Revolución Nacional, un desprendimiento del viejo PS. Luego del golpe de Estado que derribó al gobierno peronista en 1955, la principal acción de

\footnotetext{
${ }^{2}$ Martín Mangiantini, El trotskismo y el debate en torno a la lucha armada. Moreno, Santucho y la ruptura del PRT (Buenos Aires: El Topo Blindado, 2014).
} 
Martín Mangiantini, PRT-La Verdad y el movimiento estudiantil argentino. Hacia un análisis de las estrategias de inserción y de las tensiones existentes (1968-1972) / PRT-La Verdad and the argentine student movement. Toward to the analysis of the strategies of insertion and tensions (1968-1972), Revista Izquierdas, $\mathbf{N}^{\circ} 23$, abril 2015, ISSN 0718-5049, IDEA-USACH, pp. 81-101

esta corriente se desenvolvió dentro del movimiento obrero que resistió a la Revolución Libertadora. Acorde a esta línea, impulsó el Movimiento de Agrupaciones Obreras con el objetivo de construcción de una tendencia sindical y clasista independiente y, desde 1957, comenzó a practicar el entrismo en el movimiento peronista. Esta táctica consistía en la entrada de los militantes a un movimiento ideológicamente no revolucionario pero absolutamente mayoritario entre los sectores trabajadores (como era el peronismo) con la pretensión de influir en un viraje ideológico de sus integrantes hacia posiciones de izquierda. Con esta orientación, esta corriente comenzó a editar el periódico Palabra Obrera, utilizado para relacionarse con los diversos sectores de la vanguardia fabril. Tal fue la importancia de esta herramienta de difusión que al propio grupo se lo empezó a conocer y denominar con ese nombre. En 1964, Palabra Obrera consideró culminada la experiencia del entrismo y, en la búsqueda de confluencia con otras vertientes revolucionarias, se fusionó con el FRIP dando origen al PRT cuya efímera duración, como se mencionó, se prolongó durante tres años.

En la práctica, para la tendencia dirigida por Moreno, la ruptura del PRT significó un profundo golpe que se manifestó con la migración de cuadros históricos y de jerarquía de la organización que se sumaron a las filas de los hermanos Santucho como así también en la pérdida prácticamente íntegra de regionales de peso como Córdoba, Tucumán y el Litoral. El flamante PRT - LV mantuvo su estructura casi intacta en el Gran Buenos Aires (con mayor fortaleza en la zona Norte) y en la región de La Plata, Berisso y Ensenada manteniendo una estructura con una cifra inferior a los 300 militantes. En este sentido, la inserción en el movimiento estudiantil fue también parte de una política tendiente hacia la concreción de una reestructuración partidaria, necesaria tras la merma de la militancia que significó la ruptura acaecida. No obstante, la búsqueda de un crecimiento partidario a partir de una inserción en el movimiento estudiantil no era una novedad en el seno de esta corriente política sino que, con matices, había sido una constante en su trayectoria.

La ruptura del PRT acaecida en 1968 redundó en una polémica que incluyó temáticas de diversa índole y discusiones de corte teórico siendo uno de los aspectos de mayor peso la caracterización en torno al sujeto revolucionario, elemento que, al mismo tiempo, se hallaba ligado con la estrategia propicia para la transformación radical de la sociedad y con el papel que una organización revolucionaria desempeñaría en tal contexto. La radicalización obrera y juvenil que significaron procesos sucedidos entre los años 1967 y 1969, tales como el Mayo Francés, la Primavera de Praga, la rebelión estudiantil en México o las masivas protestas juveniles contra la guerra de Vietnam pusieron de manifiesto el retorno a las acciones de masas que tuvieron tanto al proletariado como a una juventud radicalizada como protagonistas. En esta coyuntura, el PRT - LV pronosticó la apertura, a nivel mundial, de una combinación de diversos métodos de lucha y formas organizativas ${ }^{3}$ e identificó un posible giro venidero en los métodos de enfrentamiento al sistema capitalista que

\footnotetext{
3 "Informe internacional”, Comité Central del PRT-LV, Marzo de 1969 [Agregado a mano: Crítica al Doc. Latinoamericano de Hansen - Crítica al Doc. Internacional de Livio - Documento previo al IX Congreso de la IV Internacional], p. 3.
} 
Martín Mangiantini, PRT-La Verdad y el movimiento estudiantil argentino. Hacia un análisis de las estrategias de inserción y de las tensiones existentes (1968-1972) / PRT-La Verdad and the argentine student movement. Toward to the analysis of the strategies of insertion and tensions (1968-1972), Revista Izquierdas, $\mathbf{N}^{\circ} 23$, abril 2015, ISSN 0718-5049, IDEA-USACH, pp. 81-101

transformarían a las manifestaciones multitudinarias y desorganizadas en huelgas parciales o generales con características insurreccionales o preinsurreccionales ${ }^{4}$.

A partir de diversos conflictos acaecidos en 1968, este partido vislumbró el inicio de una etapa que ubicaría al movimiento obrero y urbano a la cabeza de las luchas a través de sus métodos tradicionales (como las huelgas y tomas de fábrica) en combinación con otros nuevos $^{5} \mathrm{y}$, en concordancia con ello, comenzó su reconstrucción tras reafirmar el paradigma organizativo partidario leninista, pugnar por la penetración en el proletariado a partir de la participación en sus movilizaciones y, paralelamente, presentarse como alternativa de dirección de sus organismos ya existentes. En relación con ello, se planteó como premisa que un partido revolucionario no debía posicionarse por sobre los organismos que las propias masas se daban (como, por ejemplo, las comisiones internas y cuerpos de delegados) sino pugnar por su inserción en ellos a partir del esbozo de aquellas reivindicaciones que fueran capaces de colaborar con la elevación de las luchas existentes ${ }^{6}$.

Esta concepción se reafirmó y profundizó a partir del estallido del Cordobazo en 1969 y del cambio coyuntural que implicó. Este partido caracterizó que esta insurrección generó en Argentina una situación prerrevolucionaria lo que se justificó con la visualización de cuatro características identificadas en la coyuntura política iniciada luego de este hecho. En primer lugar, la presencia de una situación de inestabilidad de los sectores burgueses que comenzaban a mostrar disputas entre sí de un modo más álgido. En segundo orden, la creciente oposición al gobierno de una pequeña-burguesía radicalizada. Por otra parte, la disposición para la lucha del movimiento obrero demostrada en la contundencia de las huelgas generales y, por último, el surgimiento de una vanguardia estudiantil y obrera, ya revolucionaria o con tendencias a adquirir posiciones de esa índole, dispuesta al enfrentamiento contra el gobierno y a la formación durante los conflictos de embriones de nuevas direcciones y organizaciones de masas que reflejaban la incipiente unidad obreroestudiantil ${ }^{7}$. Si el Cordobazo no produjo la caída definitiva del régimen, su causa fue el retraso en la formación de una dirección clasista y en la conservación por parte de la burocracia sindical del dominio de los organismos de masas lo que impidió que la clase obrera gestara un cambio radical en la relación de fuerzas. Para esta corriente, las bases obreras compartían estas posturas pero ellas aún se expresaban más como un repudio y desprestigio de la burocracia sindical que en el reconocimiento y conformación de nuevas direcciones clasistas ${ }^{8}$. Sobre esta base, este partido reafirmó como tareas centrales la conquista de los cuerpos de delegados y comisiones internas de fábrica y un fortalecimiento como organización ligada a esta línea. Tal determinación implicó la necesidad de reestructurar un partido político mermado por la ruptura preexistente a partir de la puesta en

\footnotetext{
4 "Proyecto de tesis sobre la situación latinoamericana”, Comité Central del PRT-LV, Julio de 1969, p. 1.

${ }^{5}$ Ernesto González, El trotskismo obrero e internacionalista en la Argentina. Tomo 3: Palabra Obrera, el PRT y la Revolución Cubana, Volumen 2 (1963-1969) (Buenos Aires: Antídoto, 1999).

${ }^{6}$ Nahuel Moreno, Argentina y Bolivia: Un balance (Buenos Aires: Pluma, 1973).

7 "Tesis sobre la situación nacional después de las grandes huelgas generales" [Firmado por "NM" - Nahuel Moreno]. Comité Central del PRT-LV, Junio de 1969, p.1.

8 “1969”. Comité Central del PRT-LV, 1969, p. 2.

9 “Tesis sobre la situación nacional después de las grandes huelgas generales”. Op. Cit., pp. 7-8.
} 
Martín Mangiantini, PRT-La Verdad y el movimiento estudiantil argentino. Hacia un análisis de las estrategias de inserción y de las tensiones existentes (1968-1972) / PRT-La Verdad and the argentine student movement. Toward to the analysis of the strategies of insertion and tensions (1968-1972), Revista Izquierdas, $\mathbf{N}^{\circ} 23$, abril 2015, ISSN 0718-5049, IDEA-USACH, pp. 81-101

práctica de una diversidad de estrategias con la pretensión de insertarse en el movimiento obrero, en sus organismos de lucha y en su conflictividad. De ellas, la experiencia más paradigmática recayó en la estrategia de la proletarización de la militancia partidaria que implicó el vuelco a la actividad política en el ámbito fabril de diversos militantes antes insertos en otras tareas ${ }^{10}$.

A partir de una caracterización que, como se expresó, privilegiaba una inserción militante en el movimiento obrero y en sus órganos de lucha, es preciso analizar la relación forjada entre el PRT - LV y el estudiantado como sujeto y la búsqueda de un accionar político partidario ligado a este sector. En primer orden, existió una influencia de la coyuntura internacional, particularmente a partir del estallido del Mayo Francés y, con éste, de la influencia de estructuras de allí tales como la Liga Comunista Revolucionaria (LCR) y de dirigentes como Ernest Mandel que reivindicaron el papel de una juventud radicalizada como sujeto revolucionario ${ }^{11}$. En este aspecto, se desprende de la documentación interna que el Mayo Francés significó un impacto en las conceptualizaciones de esta corriente política. Una vez acontecido, se identificó el inicio de una nueva dirección política. En relación con ello, el estudiantado era visto como una vanguardia de dicha insurrección dado que las corrientes revolucionarias estudiantiles produjeron un desplazamiento tanto del reformismo como de los dirigentes del Partido Comunista a diferencia de la clase obrera que, sin bien movilizada, no logró una superación de las direcciones ligadas a esta estructura ${ }^{12}$.

En segundo lugar, se percibe una explicación vinculada al contexto argentino. Como señala Terán ${ }^{13}$, el golpe de Estado de 1966 dinamizó y benefició a una oposición revolucionaria antes fragmentada dado que produjo, por un lado, la radicalización de sectores intelectuales y políticos y, por otro, achicó las diferencias dentro del campo opositor al que preparó para su lanzamiento a la acción en la década siguiente. En relación con ello, la aparición de una oposición por parte de la sociedad civil a la dictadura de Onganía provino, paulatinamente, de diversas fuentes. Uno de los primeros actores en reaccionar contra la política gubernamental fue el movimiento estudiantil como expresión de repudio a la política de intervención de las universidades sostenida por el gobierno. Este sector, notoriamente influido por un contexto mundial que tenía a la juventud como protagonista de diversas movilizaciones de masas que pugnaban por la transformación radical de la sociedad, fue atravesado por el debate político de época y por la dicotomía entre las vertientes reformistas y revolucionarias existentes a nivel mundial. En este marco, en Argentina, la "vanguardia

\footnotetext{
${ }^{10}$ Martín Mangiantini, "Clase y partido. Surgimiento, proletarización y militancia fabril del PRT - La Verdad (1968-1972)”, Archivos de Historia del Movimiento Obrero y la Izquierda (2014).

${ }^{11}$ Entrevista a Aldo Casas realizada por el autor, Buenos Aires, 25-09-2012.

${ }_{12}$ "Boletín interno sobre la insurrección francesa”, BI del PRT-LV, 1 de julio de 1968, p. 2.

${ }^{13}$ Oscar Terán, Nuestros años sesenta. La formación de la nueva izquierda intelectual argentina, 1956-1966, (Buenos Aires: Puntosur, 1991).
} 
Martín Mangiantini, PRT-La Verdad y el movimiento estudiantil argentino. Hacia un análisis de las estrategias de inserción y de las tensiones existentes (1968-1972) / PRT-La Verdad and the argentine student movement. Toward to the analysis of the strategies of insertion and tensions (1968-1972), Revista Izquierdas, $\mathbf{N}^{\circ} 23$, abril 2015, ISSN 0718-5049, IDEA-USACH, pp. 81-101

estudiantil” comenzó a virar paulatinamente hacia posiciones radicalizadas ${ }^{14}$. Sobre todo en el interior del país, se experimentaba la novedad de un estudiantado universitario que establecía lazos, cada vez más estrechos, con el movimiento obrero.

Sobre esa base, este partido brindará una importancia primaria a su inserción como organización en el movimiento estudiantil. Para esta corriente, este actor representaba a un sector de la población que servía como reflejo de la sociedad en su conjunto. En esta línea, argumentaba que si la sociedad marchaba sin grandes contradicciones, este sector, en líneas generales, reflejaba tal situación convirtiéndose en una capa relativamente acomodaticia. Por el contrario, si la sociedad se encontraba roída en profundas tensiones y en una crisis creciente, se convertía en uno de los primeros en captar tal coyuntura y anticipar, con sus luchas, diversas consignas que afectaban al conjunto de la población y anunciaban la lucha de clases venidera $^{1.5}$. En relación con ellos, en el marco de un contexto mundial de radicalización marcado por las rebeliones contra la guerra de Vietnam y el ascenso de masas a nivel internacional, el estudiantado jugaría, según este análisis, un papel preponderante:

(...) el estudiantado, el sector más sensible de la sociedad por estar desligado de la producción y por la forma intelectual (que su misma actividad le impone) de aprehender la realidad, percibe esa crisis del sistema capitalista de conjunto, percibe ese ascenso de la revolución mundial y da un paso adelante: se moviliza con consignas y objetivos revolucionarios anticipándose al ascenso de las propias masas obreras de sus países ${ }^{16}$.

El PRT - LV caracterizó que, en la etapa económica abierta durante el proceso de Onganía, el movimiento estudiantil cobró una importancia mayor como sujeto. La explicación de ello recayó en que el modo de acumulación originado con el inicio de la dictadura de 1966, precisaba de una cantidad cada vez mayor de técnicos calificados y profesionales de modo que, el capitalismo se veía obligado a desarrollar y popularizar la enseñanza universitaria y técnica. En paralelo a ello, se había experimentado una ampliación de la matrícula universitaria que permitió el ingreso de hijos provenientes de los sectores trabajadores. Por ello, esta corriente pronosticó, a su vez, que esta ampliación generaría diversas contradicciones, principalmente, la preparación para un mercado de trabajo que ahogaba la personalidad y el desarrollo del individuo y formaba profesionales en razón de las necesidades de las grandes empresas sin dejar lugar a las iniciativas individuales ${ }^{17}$.

En otro orden, como se manifiesta en el siguiente testimonio, existió un análisis positivo del estudiante como sujeto tanto por su papel como intelectual como, así también, por la mayor disposición para la participación política que manifestaba:

\footnotetext{
${ }^{14}$ Mónica Gordillo, "Protesta, rebelión y movilización: de la resistencia a la lucha armada, 1955-1973", en Daniel James, Nueva Historia Argentina. Tomo IX: Violencia, proscripción y autoritarismo (1955-1976) (Buenos Aires: Sudamericana, 2003).

${ }_{15}^{15}$ "El movimiento estudiantil y nuestra política”, Comité Central del PRT-LV, 1968, p. 1.

${ }_{16}$ "El movimiento estudiantil mundial”, Comité Central del PRT-LV, 06-07-1968, p. 1.

${ }^{17}$ Ibídem, pp. 1-2.
} 
(...) No éramos sectarios con respecto al movimiento estudiantil. Le dábamos mucha importancia a tener influencia al movimiento estudiantil porque era de donde se generaban los cuadros, con capacidad intelectual y de disposición de dar la vida. Porque el obrero muchas veces viene con su mujer, con su familia, tiene presiones, el estudiante no. La misma organización y la misma clase lo formaban. Por eso tenía mucha importancia $^{18}$.

Por último, se desprende del análisis de esta organización política la afirmación sobre la imposibilidad del movimiento estudiantil de jugar un papel independiente o autónomo. Dado que este sector no gozaba del carácter de clase social, su agitación y movilización sólo tenía perspectivas revolucionarias si se ligaba con el movimiento obrero o antiimperialista de las grandes masas coloniales. Para el PRT - LV, si ello no ocurría, el movimiento estudiantil recaía finalmente en planteos anárquicos, en desesperación, con un consecuente vacío de sus direcciones y tendencias. A partir de este análisis se explicaba el carácter cambiante de este sujeto, los frecuentes cambios de liderazgos, las rupturas y los momentos de radicalización y, en relación con ello, la necesidad de una organización revolucionaria de prepararse para intervenir en este sujeto donde, en poco tiempo, surgían y se desarrollaban movilizaciones importantes, perdían la dirección dirigentes y organizaciones tradicionales para surgir otras que, en muchos casos, quedaban en el camino ${ }^{19}$.

Entre 1968 y 1972, el PRT - LV esbozó su análisis del movimiento estudiantil como sujeto ligado a los diversos (y notorios) cambios políticos que se sucedieron en tal coyuntura. Es evidente el quiebre que el estallido del Cordobazo produjo en los análisis de esta corriente. Antes de su concreción, se percibía un momento de retroceso del estudiantado luego de la aplicación de medidas limitacionistas por parte del gobierno dictatorial ${ }^{20}$. Ante tal circunstancia, el papel de un partido revolucionario no consistía en una búsqueda de una inserción política en el conjunto del estudiantado sino, particularmente, en su vanguardia a través del impulso de campañas que permitieran su participación tales como, el apoyo a la resistencia de Vietnam o el impulso de la OLAS por parte de la dirección cubana ${ }^{21}$.

El Cordobazo produjo un viraje en los análisis tras la importante participación del movimiento estudiantil del interior del país en los enfrentamientos contra el aparato represivo estatal. Para el PRT - LV, se trató de movilizaciones que, iniciadas con reivindicaciones específicamente estudiantiles o democráticas, en su desarrollo terminaron por cuestionar (directa o indirectamente) la existencia misma del gobierno. La otra característica fue el surgimiento de una nueva vanguardia que impulsó y participó de tales

\footnotetext{
${ }^{18}$ Entrevista a Nora Ciapponi realizada por el autor, Buenos Aires, 15-09-2012.

${ }^{19}$ "El movimiento estudiantil y nuestra política”, Op. Cit., p. 1.

${ }^{20}$ La incorporación de cupos máximos para el ingreso a las carreras universitarias fue una política estatal desde el golpe de 1966 que supuso resistencias por parte del estudiantado.

${ }_{21}^{21}$ "La revolución latinoamericana, Argentina y nuestras tareas”, IV Congreso Nacional del PRT-LV, 1968, p. 28.
} 
Martín Mangiantini, PRT-La Verdad y el movimiento estudiantil argentino. Hacia un análisis de las estrategias de inserción y de las tensiones existentes (1968-1972) / PRT-La Verdad and the argentine student movement. Toward to the analysis of the strategies of insertion and tensions (1968-1972), Revista Izquierdas, $\mathbf{N}^{\circ} 23$, abril 2015, ISSN 0718-5049, IDEA-USACH, pp. 81-101

acciones pero que, a su vez, trajo como contrapartida una profundización de la crisis de los organismos y direcciones tradicionales que, ya habían perdido el control del movimiento estudiantil y no lograron dirigir el nuevo ascenso. Daba cuenta de ello el surgimiento de nuevos organismos, como las coordinadoras o cuerpos de delegados, que agruparon a esta vanguardia y reivindicaron la participación directa de las bases ${ }^{22}$.

Al mismo tiempo, esta organización analizó los matices del papel jugado por el estudiantado en los comienzos de este ascenso de masas. La desigualdad en el grado de masividad, combatividad y contundencia de las acciones a escala nacional; la tendencia a rechazar los organismos tradicionales del movimiento estudiantil; y una aceptación (aunque abstracta) de la necesidad de vinculación con el movimiento obrero fueron sus rasgos centrales $^{23}$.

Por último, una vez concretado el Cordobazo, este partido pronosticó que, una estrategia de freno a la crisis por parte del gobierno, recaería en el otorgamiento paulatino de libertades democráticas retaceadas lo que tendría como objetivo descomprimir la tensión con diversos actores sociales, entre ellos, parte del estudiantado. En relación con ello, alertó que la posibilidad de un proceso de paulatinas reformas democráticas dividiría al movimiento estudiantil y frenaría tanto su participación en las diversas insurrecciones o semiinsurrecciones acaecidas como el esbozo de unidad con el movimiento obrero a partir de la adopción, de ciertos sectores, de una política de adhesión y entusiasmo por la obtención de las libertades democráticas. En definitiva, se pronosticaba que la política gubernamental hacia el estudiante recaería en pugnar por la inserción de este actor social en una estrategia reformista que sirviera como parte de una barrera de contención hacia las tendencias revolucionarias $^{24}$. Para esta estructura, se avecinaba una coyuntura que incluiría la posibilidad de un retorno al sistema electoral, el resurgimiento del peronismo y la continuidad de luchas del movimiento obrero que impactarían a este actor. Las dos primeras de estas posibilidades ejercerían una influencia negativa en el estudiantado movilizado (dado que lo volcarían hacia salidas de tipo reformistas) mientras que la última sería un aspecto positivo que esta organización debía sostener a partir de su inserción en este sujeto social apostando a la continuidad de la participación estudiantil en este tipo de movilizaciones y a la profundización de su unidad con la clase obrera ${ }^{25}$.

La fallida experiencia de Levingston, la llegada de Lanusse al poder, la profundización de la conflictividad social con insurrecciones como el Viborazo y, finalmente, el impulso por parte del gobierno de una transición democrática a través del Gran Acuerdo Nacional (GAN) también condicionó el análisis que el PRT - LV desarrolló con respecto al movimiento estudiantil. Al proclamarse la estrategia del GAN, pronosticó que ella tendería a consolidarse dado que Perón aceptaría formar parte de tal juego político ${ }^{26}$. A este análisis, agregó que, ante tal coyuntura, el peronismo experimentaría la última etapa de su crisis. Para esta corriente, el peronismo vivía un momento en el que tendía a ganar apoyo en sectores de

\footnotetext{
22 "Proyecto de documento estudiantil”, Comité Central del PRT-LV, 1969, pp. 2-3.

${ }_{23}$ "La Universidad de Buenos Aires”, Comité Ejecutivo del PRT-LV, 1969, pp. 1-2.

${ }^{24}$ "Proyecto de documento estudiantil", Op. Cit., p.2.

${ }^{25}$ Ibídem, p. 5.

${ }^{26}$ "Situación nacional”, IV Congreso Nacional del PRT-LV, Septiembre de 1971, p. 4.
} 
Martín Mangiantini, PRT-La Verdad y el movimiento estudiantil argentino. Hacia un análisis de las estrategias de inserción y de las tensiones existentes (1968-1972) / PRT-La Verdad and the argentine student movement. Toward to the analysis of the strategies of insertion and tensions (1968-1972), Revista Izquierdas, $\mathbf{N}^{\circ} 23$, abril 2015, ISSN 0718-5049, IDEA-USACH, pp. 81-101

la pequeña burguesía, tales como el estudiantado pero, paralelamente, perdía peso en la dirección de los conflictos obreros que últimamente se habían producido como, por ejemplo, el SITRAC-SITRAM, Banco Nación, Chrysler y Petroquímica, entre otros.

Por último, planteó que la situación prerrevolucionaria que se había iniciado con el Cordobazo continuaba y vislumbró la profundización de la lucha de clases en tres sentidos diferentes. Por un lado, caracterizó que en el conjunto del movimiento obrero se desencadenarían una multitud de conflictos sindicales por razones económicas los cuales se combinarían con la crisis política del régimen que, paralelamente, afectaría la relación del movimiento obrero con el peronismo por ser este último parte de ese régimen a partir de los acuerdos con el gobierno. En segundo orden, a nivel de la vanguardia, ésta tendría la oportunidad de madurar y adquirir experiencia al calor de los diversos conflictos que se sucedieran y así se abriría la posibilidad de cuestionamiento de las bases a las direcciones burocráticas del movimiento obrero. En relación con ello, se rescataba la experiencia del SITRAC-SITRAM como uno de los embriones de nuevas expresiones de la vanguardia obrera que podrían encabezar una reestructuración contra la burocracia sindical. En tercer lugar, a nivel de los organismos de la clase y la vanguardia, se caracterizaba la posibilidad de maduración de aquellos embriones de nuevas formas de organización tales como los comités de huelga, las nuevas comisiones internas, las coordinadoras interfabriles y los comités obrero-estudiantiles ${ }^{27}$.

En lo pertinente específicamente al ámbito universitario, el PRT - LV caracterizó que el impulso gubernamental del GAN traería consigo diversas consecuencias en su seno. En primer lugar, las universidades se transformarían en escenarios para las disputas ínterburguesas existentes en esta etapa de transición. Así, una burguesía nacional, fundamentalmente peronista (cuya expresión central era la Hora del Pueblo) comenzaría a presionar para recuperar el control sobre determinadas carreras y universidades y penetrar en otras. Al mismo tiempo, los sectores ligados al desarrollismo presionarían por imponer sus elencos y reestructurar carreras y programas acordes a las necesidades de las nuevas y grandes empresas ${ }^{28}$.

En segundo lugar, este partido vislumbraba el inicio de una batalla ideológica y política con respecto a la salida para el país. En este sentido, afirmaba que el estudiantado estaría atravesado por diversas salidas caracterizadas como patronales (como la Hora del Pueblo, el desarrollismo y el Encuentro Nacional de los Argentinos), la variante ultraizquierdista que sostenía la consigna "Ni golpe ni elección, revolución” (impulsada por diversas corrientes como las maoístas) y una posición pro-obrera sostenida por el propio PRT - LV. Así, se pronosticaba, este proceso acentuaría la polarización del movimiento estudiantil y dificultaría la unidad para la acción con programas y objetivos comunes ${ }^{29}$.

$$
* * *
$$

\footnotetext{
${ }^{27}$ Ibídem, p. 6.

${ }_{28}$ "Informe estudiantil”. IV Congreso Nacional del PRT-LV, 1971, p. 2.

${ }^{29}$ Ibídem, p. 3.
} 
Martín Mangiantini, PRT-La Verdad y el movimiento estudiantil argentino. Hacia un análisis de las estrategias de inserción y de las tensiones existentes (1968-1972) / PRT-La Verdad and the argentine student movement. Toward to the analysis of the strategies of insertion and tensions (1968-1972), Revista Izquierdas, $\mathbf{N}^{\circ} 23$, abril 2015, ISSN 0718-5049, IDEA-USACH, pp. 81-101

En la coyuntura descripta, el PRT - LV coexistía al interior del movimiento estudiantil con numerosas corrientes políticas de diversa índole con las que disputaba la dirección de este actor. Por un lado, se encontraban aquellas agrupaciones denominadas por el PRT - LV como “corrientes burguesas”. Bajo esta nomenclatura se incluía a las diversas expresiones universitarias peronistas como el Frente Estudiantil Nacional (FEN) y otras agrupaciones menores como la JRP, el MRP y el MLN. Al FEN, el PRT - LV lo caracterizaba como un agrupamiento que experimentó un viraje del castrismo hacia la derecha y que, en esa coyuntura, se había convertido en el brazo estudiantil de la CGT de los Argentinos de Raimundo Ongaro la cual era caracterizada como una oposición burguesa al gobierno dictatorial iniciado en 1966. En segundo lugar, se incluía a la democracia cristiana, con sus diversas expresiones a nivel nacional de diversa línea tales como, por ejemplo, el Ateneo de Santa Fe (caracterizado como una corriente pequeño-burguesa con inclinaciones de izquierda), el humanismo o el integralismo cordobés ${ }^{30}$.

En un segundo plano se ubicaba el Partido Comunista (PC), golpeado a nivel estudiantil tras la ruptura del sector que, posteriormente, conformaría el Partido Comunista Revolucionario (PCR). El PC era analizado como una corriente con una militancia estudiantil numerosa y activa pero tendiente a motorizar diversas consignas mínimas y negarse, al mismo tiempo, a ligar las mismas con otras transicionales que permitieran una superación del conflicto y de la conciencia del estudiantado. Por su parte, el PCR fue paulatinamente caracterizado como una corriente "ultraizquierdista", denominación que respondía a la denuncia de actitudes sectarias que dividían al movimiento estudiantil e impedían una eficaz resistencia contra la dictadura y sus políticas universitarias primando la propia construcción organizacional al pugnar por el desplazo de las restantes corrientes revolucionarias de los órganos de representación ${ }^{31}$. De modo similar, el PRT - LV caracterizó a la otra expresión del maoísmo argentino, Vanguardia Comunista.

En la búsqueda de un crecimiento partidario y de una construcción política ligada a aquellos sectores considerados de vanguardia, el PRT - LV desarrolló diversas estrategias de inserción en el seno del movimiento estudiantil. Un elemento de inserción ponderado por esta corriente recayó en el papel que podrían cumplir las consignas motorizadas por un partido revolucionario como medio de elevación del nivel de conciencia de las masas. Éstas tenían como objetivo su capacidad de movilización y, por ello, debían reflejar las necesidades y el nivel de conciencia existente en cada momento determinado (Moreno, 1989: 212-213). Vinculado a esta problemática, esta corriente utilizó dos conceptos para poner en práctica su estrategia discursiva de inserción en la clase obrera: la propaganda y la agitación. La primera de estas herramientas era identificada como la propiedad de una organización de brindar una elevada cantidad de ideas a un público reducido e incluía desde la formación para la propia militancia partidaria hasta las charlas individuales con el activismo al que se le describía la situación nacional, internacional, el programa del partido o las diferencias con otras

\footnotetext{
${ }^{30}$ "El movimiento estudiantil y nuestra política”. Op. Cit., pp. 15-16.

${ }^{31}$ La Universidad de Buenos Aires”. Op. Cit., p. 4 y "El movimiento estudiantil y nuestra política”. Op. Cit., p. 19.
} 
Martín Mangiantini, PRT-La Verdad y el movimiento estudiantil argentino. Hacia un análisis de las estrategias de inserción y de las tensiones existentes (1968-1972) / PRT-La Verdad and the argentine student movement. Toward to the analysis of the strategies of insertion and tensions (1968-1972), Revista Izquierdas, $\mathbf{N}^{\circ} 23$, abril 2015, ISSN 0718-5049, IDEA-USACH, pp. 81-101

organizaciones revolucionarias (Moreno, 1989: 196). Por su parte, la agitación era la capacidad de levantar unas pocas consignas (o bien, una sola) que dieran una salida para la lucha que el movimiento de masas tuviera planteada en un momento determinado. Esta herramienta se materializó a través de volantes, pintadas, charlas en los cursos o, en el marco de las concentraciones, mediante el uso de la palabra ${ }^{32}$.

A lo largo de estos años, la militancia del PRT - LV desarrolló al interior del movimiento estudiantil diversos tipos de consignas. Por un lado, aquellas ligadas a la coyuntura internacional siendo el apoyo a la revolución vietnamita y el retiro de las tropas norteamericanas uno de los ejemplos más relevantes. La documentación da cuenta de la realización de pintadas, volantes y actos relámpagos en los cursos, entre otras acciones pertinentes a esta temática ${ }^{33}$. Otros ejemplos fueron actividades relacionadas al Mayo Francés, a la Primavera de Praga o en los aniversarios de la muerte del Che Guevara ${ }^{34}$. En segundo lugar, existió una primacía por aquellas consignas que dieran cuenta de algún tipo de conflicto obrero con la consecuente búsqueda de apoyo al mismo por parte del estudiantado. Existen diversas experiencias como, por ejemplo, la búsqueda de los militantes del PRT - LV de difundir en el ámbito universitario el conflicto desatado en la planta de Peugeot de La Plata en 1968 y la pugna por formar una comisión de solidaridad obreroestudiantil y la edición de un boletín de huelga ${ }^{35}$. En relación con ello, se reproduce la necesidad de promoción de actividades de ligazón con el movimiento obrero tales como la participación en los conflictos o los actos en puertas de fábrica a través de una política de propaganda de estas luchas entre el estudiantado y la búsqueda de que sean los mismos organismos estudiantiles (y no simplemente los militantes de una estructura partidaria) los que tomen como propias esas tareas ${ }^{36}$.

Por último, se encuentran aquellas consignas y actividades que tenían como ejes las problemáticas de la propia universidad pero que, al mismo tiempo, permitieran una elevación de la conciencia e involucraran, paulatinamente, otras temáticas. En relación con ello, consignas como la derogación de los ingresos y de toda forma de limitación en paralelo al aumento del presupuesto con control estudiantil se ligaban a la exigencia de derogación de toda ley y decreto que apoyara tales restricciones así como al aumento presupuestario en detrimento de las ganancias de los grandes monopolios y del gasto destinado al aparato represivo $^{37}$. En segundo orden, el fin de los planes de reestructuración de las carreras por parte del gobierno y el control estudiantil de las reformas de los planes de estudio se ligaba a demandas más generales como, por ejemplo, el freno a la penetración abierta en las universidades por parte de los intereses de los grandes monopolios o la lucha por concursos verdaderamente democráticos con control de los estudiantes, entre otras ${ }^{38}$. A su vez, la

\footnotetext{
${ }_{22}$ "Sobre agitación y propaganda (para BI)", Comité Ejecutivo del PRT-LV, 1969, p. 1.

${ }^{33}$ "Orden del día del C.C.", Comité Central del PRT-LV, Mayo de 1968, pp. 1-2 y "El movimiento estudiantil y nuestra política”, Op. Cit., pp. 7-9.

${ }^{34}$ "El movimiento estudiantil y nuestra política", Op. Cit., p. 21.

${ }^{25}$ Ibídem, p. 11.

${ }^{36}$ Ibídem, p. 21.

${ }^{37}$ "Informe estudiantil", IV Congreso Nacional del PRT-LV, 1971, p. 4.

${ }^{38}$ Ibídem, p. 5.
} 
Martín Mangiantini, PRT-La Verdad y el movimiento estudiantil argentino. Hacia un análisis de las estrategias de inserción y de las tensiones existentes (1968-1972) / PRT-La Verdad and the argentine student movement. Toward to the analysis of the strategies of insertion and tensions (1968-1972), Revista Izquierdas, $\mathbf{N}^{\circ} 23$, abril 2015, ISSN 0718-5049, IDEA-USACH, pp. 81-101

exigencia de una total autonomía para la universidad y un gobierno de toda su población democráticamente representada que, según sostenía esta corriente, no eran un fin en sí mismo sino que se hallaban ligadas al objetivo superior de posicionar a la universidad al servicio de la movilización obrera ${ }^{39}$.

Independientemente del discurso agitativo y propagandístico, el PRT - LV desarrolló diversas estrategias para forjar una inserción en el seno del estudiantado. En primer lugar, la necesidad de una participación activa de cada militante en los distintos cursos y materias. En relación con ello, se argumentaba la necesidad de experimentar un contacto cotidiano con los estudiantes y no hacerse presente en las divisiones en los momentos de dar una línea política. Al mismo tiempo, se manifestaba que los grupos de estudio y las preparaciones colectivas de una materia eran también formas efectivas de entablar lazos con los pares ${ }^{40}$. En segundo orden, este partido sostuvo la necesidad de construcción de tendencias estudiantiles revolucionarias, esto es, agrupaciones universitarias que tuvieran un cierto grado de autonomía con respecto a los equipos estudiantiles orientados por el partido. El propósito de este planteo recaía en la creación de organismos más amplios que los núcleos partidarios con un doble objetivo: por un lado, generar un espacio de acercamiento propicio para una futura captación y, por otro, separar con mayor rigurosidad a los militantes del partido de los simpatizantes y a aquéllos que sólo acordaban con la política universitaria a los efectos de evitar problemáticas ligadas a un contexto de clandestinidad y necesidad de medidas de seguridad $^{41}$. Por último, en la medida en que se produjo la transición hacia un paulatino retorno electoral con la posibilidad de ciertas aperturas democráticas, a estas estrategias antes mencionadas, el PRT - LV incorporó ciertas actividades que conllevaban una mayor exposición tales como charlas, cursos de formación o la venta del diario, entre otros $\operatorname{recursos}^{42}$.

Como se dijo anteriormente, la ruptura del PRT en 1968 supuso un duro golpe para la corriente encabezada por Moreno. En términos cuantitativos, la división de este partido generó la formación de dos organizaciones divergentes prácticamente igualadas en su militancia. No obstante, para la facción que conformaría el PRT - LV, este quiebre implicó un revés en términos políticos dada la fuga a la corriente de Santucho de importantes e históricos cuadros con participación en las filas del morenismo. Al mismo tiempo, regiones fundamentales como Córdoba, Tucumán o el Litoral fueron hegemonizadas por el PRT - El Combatiente lo que supuso la necesidad de una reestructuración absoluta de esta corriente. Si bien una de las principales estrategias para la reorganización y reconstrucción partidaria fue la política de la proletarización de la militancia, la inserción en el movimiento estudiantil fue una constante sostenida por esta organización.

\footnotetext{
${ }^{39}$ Ibídem, p. 5.

40 "Informe de actividades", Comité Central del PRT-LV, Julio de 1969, p. 4.

${ }^{41}$ "Proyecto de documento estudiantil - Segunda parte”, Comité Central del PRT-LV, 1969, pp. 8-9.

${ }^{42}$ Entrevista a Carlos Chino Moya realizada por el autor, Buenos Aires, 24-09-2013.
} 
Martín Mangiantini, PRT-La Verdad y el movimiento estudiantil argentino. Hacia un análisis de las estrategias de inserción y de las tensiones existentes (1968-1972) / PRT-La Verdad and the argentine student movement. Toward to the analysis of the strategies of insertion and tensions (1968-1972), Revista Izquierdas, $\mathbf{N}^{\circ} 23$, abril 2015, ISSN 0718-5049, IDEA-USACH, pp. 81-101

En relación con lo antes dicho, Córdoba y Tucumán fueron dos provincias paradigmáticas. Ambas tuvieron dos aspectos en común. En primer lugar, su importancia política como epicentros de estallidos populares de magnitud que fueron relevantes para el desgaste de la dictadura imperante en Argentina. Particularmente el Cordobazo de 1969 y, un año después, el Tucumanazo, fueron insurrecciones emblemáticas que dieron cuenta del grado de radicalización naciente y del surgimiento de una nueva vanguardia obrera y estudiantil. Paradójicamente, en ambas provincias, la ruptura del PRT, en 1968, determinó que una amplia mayoría de la militancia de este partido se volcara hacia las filas del PRT EC. Para el PRT - LV ello produjo un rasgo negativo: justamente en aquellas provincias en donde se producirían fundamentales insurrecciones, la fortaleza partidaria fue considerablemente menor. Por ende, en ambas provincias, la reestructuración partidaria se planificó desde la dirección nacional mediante la táctica de envío de cuadros medios de la organización convirtiéndolos en referentes de estos respectivos espacios. En el caso de Córdoba, inicialmente se envió como responsable de la provincia a un dirigente obrero del partido en Buenos Aires que había encabezado la huelga de Citroën de 1969 mientras que en Tucumán se eligió a un militante de la corriente con trayectoria tanto en el movimiento estudiantil en La Plata como entre los trabajadores de la carne en Berisso.

En estas dos provincias, por diversas razones, la problemática central experimentada recayó en sus intentos de inserción en la clase obrera. En este sentido, la estrategia de la proletarización desarrollada con masividad en Buenos Aires se reveló inconducente. En el caso de Córdoba, puede esbozarse como una de las explicaciones posibles la existencia de un amplio abanico de organizaciones revolucionarias con una militancia obrera forjada con preexistencia a la reconstrucción del PRT - LV. En relación con ello, además del peso del PRT - EC, el maó́smo tuvo en esta provincia una militancia notable tanto a nivel estudiantil como en el ámbito obrero (la figura de René Salamanca, dirigente del SMATA y militante del PCR, o la inserción de Vanguardia Comunista en los sindicatos SITRAC - SITRAM son algunos ejemplos), el PC (relacionado, aunque nunca de forma explícita, con la figura de Agustín Tosco), el peronismo a través de diversas expresiones como el FEN y, en menor medida, Política Obrera (también con influencia en algunas industrias pertenecientes al SMATA) u organizaciones más pequeñas como El Obrero, entre otras. Por su parte, en el caso de Tucumán, la dificultad para insertarse en la clase obrera no obedeció tanto a la proliferación de organizaciones en su seno como a las características que en esta provincia poseía este sujeto, más heterogéneo y, en parte, golpeado por ciertas derrotas como el cierre y racionalización de los ingenios azucareros en los inicios de la dictadura de Onganía.

Dadas las dificultades en ambas provincias para forjar una reconstrucción partidaria articulada con la inserción en el movimiento obrero, la estrategia del PRT - LV consistió en desarrollar su estructura política a partir de la militancia en el movimiento estudiantil universitario. En el caso de Córdoba, ello se justificaba aún más dado que un porcentaje destacable de trabajadores del SMATA eran, al mismo tiempo, estudiantes universitarios (por ejemplo, en la Universidad Tecnológica Nacional) ${ }^{43}$. Así, un núcleo inicial de simplemente seis miembros del PRT - LV comenzó su proceso de inserción en el espacio

${ }^{43}$ Entrevista a Orlando Mattolini realizada por el autor, Buenos Aires, 23-08-2013. 
Martín Mangiantini, PRT-La Verdad y el movimiento estudiantil argentino. Hacia un análisis de las estrategias de inserción y de las tensiones existentes (1968-1972) / PRT-La Verdad and the argentine student movement. Toward to the analysis of the strategies of insertion and tensions (1968-1972), Revista Izquierdas, $\mathbf{N}^{\circ} 23$, abril 2015, ISSN 0718-5049, IDEA-USACH, pp. 81-101

universitario $^{44}$. Paulatinamente, se consolidó como estructura en Arquitectura con un equipo que oscilaba la decena de militantes y participación en el Cuerpo de Delegados allí elegido en 1970. Una de las experiencias de las que el PRT - LV fue partícipe tuvo como epicentro justamente esta facultad. Allí se organizó un grupo de estudios denominado "Taller total", creado a partir de un relacionamiento forjado por el estudiantado con el proletariado del barrio Ferreyra, paradigmático por ser el espacio de vivienda de una importante cantidad de obreros de la FIAT. De esta relación, un sector del estudiantado motorizó una tarea de planeamiento de un proyecto de diseño urbano de este barrio obrero. Como se relata en el siguiente testimonio, esta experiencia, de la cual el PRT-LV fue parte, permitió un mayor relacionamiento del estudiantado con la clase obrera:

(...) entonces yo empiezo a tomar contacto con el movimiento obrero en forma muy directa a partir de mi propia práctica como estudiante. Voy a recorrer el barrio de Ferreyra que era un barrio construido con mucha precariedad, esa miseria de los barrios hechos para obreros donde tienen casitas muy chiquitas con pocas posibilidades de expansión y entonces nosotros hacíamos un trabajo de relevamiento de necesidades, de formas de vida, de formas de sociabilidad de la gente y tratábamos de plasmarlo en nuestros diseños. Que por supuesto tenían una carga utópica porque, en última instancia, prefigurábamos una sociabilidad que por el momento no existía o que estaba muy embrionaria, por ejemplo, como la gente salía mucho a tomar mate a la vereda en casitas que eran individuales, que tenían tapias alrededor, nosotros imaginábamos espacios más comunitarios con patios más al estilo los Ayllu, qué se yo, no sé si lo hubiéramos podido hacer, si la gente hubiera estado contenta, pero nosotros estábamos muy contentos $^{45}$.

Otros ámbitos universitarios con participación de esta corriente fueron Filosofía (en donde se realizaron campañas contra las reformas de los planes de estudio con mayor injerencia en la carrera de Psicología) y, en menor medida, Ingeniería. A partir de esta militancia estudiantil, en Córdoba comenzó a reestructurase un equipo partidario que, paulatinamente, esbozaría una cierta inserción en el espacio fabril.

Un proceso similar ocurrió en la provincia de Tucumán en donde el PRT - LV, con un equipo partidario con una cantidad de militantes inferior a los diez miembros, inició una política de militancia en las facultades de Humanidades, Arquitectura, Filosofía, Agronomía y, en menor medida, Ingeniería y Derecho ${ }^{46}$. Producto de ello, este partido conformó una agrupación universitaria denominada Movimiento Antiimperialista Universitario (MAU). Ello trajo como consecuencia la formación de una reducida estructura partidaria que le permitió posteriormente pugnar por ciertas relaciones con el movimiento obrero pero, por sobre todo, profundizar la construcción en el seno del movimiento estudiantil.

\footnotetext{
" “Córdoba”. Comité Central del PRT-LV, 1970, AA2'70, p. 1.

${ }^{45}$ Entrevista a Laura Marrone realizada por el autor, Buenos Aires, 04-09-2013.

${ }^{46}$ “Orden del día del C.E. del 17 de octubre de 1970”, Comité Ejecutivo del PRT-LV, 17-10-1970, pp. 3-4.
} 
Martín Mangiantini, PRT-La Verdad y el movimiento estudiantil argentino. Hacia un análisis de las estrategias de inserción y de las tensiones existentes (1968-1972) / PRT-La Verdad and the argentine student movement. Toward to the analysis of the strategies of insertion and tensions (1968-1972), Revista Izquierdas, $\mathbf{N}^{\circ} 23$, abril 2015, ISSN 0718-5049, IDEA-USACH, pp. 81-101

La participación de esta corriente política en el conflicto acaecido por el cierre del comedor universitario en 1970 fue el ejemplo más paradigmático de este proceso. El PRT LV fue parte de una comisión gestada para evitar el cierre del comedor al igual que el conjunto de las organizaciones revolucionarias de entonces como el PRT - El Combatiente, el PCR y el PC, entre otras.

Nosotros aplicamos la línea del programa de transición, que las tareas de controlar y dirigir, se ligaban a cuestiones políticas generales como la democracia, la lucha contra la dictadura militar, pero que había que dar respuesta al problema del comedor. Y la respuesta fue una especie de olla popular que duró más de un mes: se mangaba a la gente, a los comerciantes con un gran apoyo. Era un centro permanente de debate y discusión en una continuidad del ascenso del 69. Venían los chicos del secundario por ejemplo, de la coordinadora, y nos venían a pedir línea, a ver qué hacemos hoy ${ }^{47}$.

Este proceso de lucha específica del movimiento estudiantil se imbricó con el estallido del denominado Tucumanazo ese mismo año, una insurrección obrera y estudiantil que, durante prácticamente cuatro días obligó a un repliegue de las fuerzas represivas en la ciudad de Tucumán con una consecuente liberación de presos políticos como resultado. Ello dinamizó la lucha por el comedor universitario que no sólo permaneció abierto sino que, al mismo tiempo, amplió sus plazas de 350 a 3500 por día. Paralelamente, se votó una dirección del comedor universitario de la cual el PRT - LV fue parte con dos militantes. Tal espacio no sólo se convirtió en una conquista para aligerar los costos cotidianos del estudiantado sino también en un centro de debate del conjunto de las tendencias políticas existentes en tal coyuntura y un modo de profundización de la ligazón del estudiantado con la clase obrera.

(...) ¿Y qué era? Un comedor al servicio de las luchas estudiantiles y obreras, control estudiantil de las becas, control estudiantil de las licitaciones y participación del personal no-docente en las decisiones, es decir que tenían la puerta abierta para participar de las asambleas o de algún acontecimiento. Y con ese programa se aplica a la huelga de Panam: vienen los trabajadores de Panam en huelga a comer al comedor o se le lleva en la camioneta del comedor comida a la fábrica que estaba ocupada, y otros conflictos ${ }^{48}$.

En el ámbito de la Universidad de Buenos Aires, el PRT - LV tuvo diversos militantes en Económicas, Medicina, Arquitectura, Derecho y Exactas. No obstante, uno de los espacios con mayor construcción fue la Facultad de Filosofía con la conformación de TAREA (Tendencia de Agrupaciones Estudiantiles de Avanzada). No obstante, el tipo de proceso de radicalización experimentado por una mayoría del estudiantado en este espacio

\footnotetext{
${ }^{47}$ Entrevista a Carlos Chino Moya realizada por el autor, Buenos Aires, 27-09-2013.

${ }^{48}$ Ibídem.
} 
Martín Mangiantini, PRT-La Verdad y el movimiento estudiantil argentino. Hacia un análisis de las estrategias de inserción y de las tensiones existentes (1968-1972) / PRT-La Verdad and the argentine student movement. Toward to the analysis of the strategies of insertion and tensions (1968-1972), Revista Izquierdas, $\mathbf{N}^{\circ} 23$, abril 2015, ISSN 0718-5049, IDEA-USACH, pp. 81-101

conllevó un derrotero perjudicial para el desarrollo de esta corriente. Por ejemplo, las luchas dinamizadas en este espacio en 1971 contra las restricciones en los ingresos. Como desarrolló Bonavena ${ }^{49}$, estas luchas fueron dirigidas por aquellas tendencias que preconizaban la lucha armada, más allá de sus diferencias ideológico-programáticas (e incluso prácticas). Da cuenta de ello que un bloque conformado por las agrupaciones FAUDI (PCR), TUPAC (Vanguardia Comunista), FEN (peronismo), Carta Abierta (foquistas) y TAR (Tendencia Antiimperialista Revolucionaria, ligada al PRT - El Combatiente) votó que el PRT - LV sea expulsado del cuerpo de delegados y no pudiera participar de las asambleas estudiantiles a partir de acusaciones sobre el carácter reformista de tal corriente.

A su vez, en relación con la Facultad de Filosofía, el PRT - LV impulsó la creación de la denominada Cooperativa Obrero Estudiantil (COE). Bajo la cobertura de realizar una edición y venta de apuntes universitarios, este partido inauguró un local cercano a la facultad a través del que motorizó diversas actividades tales como la organización de charlas, reuniones con trabajadores, grupos de estudio o cursos de formación marxista ${ }^{50}$.

Otro ámbito con cierta inserción fue la Universidad de La Plata. Allí la construcción más importante se desarrolló en la Facultad de Arquitectura. Ya en 1967, la agrupación orientada por un PRT aún unificado, el MAU (Movimiento de Avanzada Universitaria) dirigía su centro de estudiantes. En 1968, esta casa de estudios fue escenario de un conflicto de relevancia iniciado por determinadas restricciones sufridas por el estudiantado como, por ejemplo, quienes quedaban libres por acumulación de ausentes, entre otras. Este conflicto se prolongó a lo largo de cien días e incluyó la toma del Rectorado de la Universidad y el PRTLV jugó un papel de codirección del mismo ${ }^{51}$. Al mismo tiempo, esta corriente tuvo militancia en Humanidades (con la creación de la agrupación VEA - Vanguardia Estudiantil de Avanzada), Ingeniería, Ciencias Naturales, Económicas y Derecho.

Por su parte, en Mar del Plata el PRT - LV tuvo participación en la Facultad de Humanidades con la agrupación ARE (Acción Revolucionaria Estudiantil) que, en un proceso de debate interno, se vio atravesada por las polémicas sobre la lucha armada y la necesidad del armamento del militante lo que derivó en su debilitamiento. En menor medida, se produjo una participación en Arquitectura, Psicología, Derecho e Ingeniería.

Por último, en Rosario, el trabajo político más sólido fue desarrollo en la Facultad de Filosofía y, en menor medida, Arquitectura, Agronomía e Ingeniería.

\footnotetext{
${ }^{49}$ Pablo Bonavena, "El cuerpo de delegados como forma organizativa del movimiento estudiantil. El doble poder en la Facultad de Filosofía y Letras de la UBA”, en Revista Lucha de Clases (Buenos Aires, 1997).

${ }^{50}$ Diego Martínez, El trotskismo morenista en la UBA (1969-1973), Ponencia, Jornadas de Sociología UBA (Buenos Aires, 2012).

${ }^{51}$ Christian Castillo, "El PRT - La Verdad durante 1968 en La Plata, Berisso y Ensenada: Una visión a través de su prensa”, en Christian Castillo y Marcelo Raimundo, El 69 platense. Luchas obreras, conflictos estudiantiles y militancia de izquierda en La Plata, Berisso y Ensenada durante la Revolución Argentina (Buenos Aires: Estudios Sociológicos Editora, 2012).
} 
Si bien la actividad estudiantil fue uno de los pilares de la militancia del PRT - LV, un elemento determinante de esta coyuntura fue la estrategia de la proletarización, la cual recayó en la inserción en el espacio fabril de aquellos miembros del partido que desarrollaban una política estudiantil universitaria de modo que, aquellos sectores provenientes de una pequeña-burguesía, se incorporaran al mundo del trabajo y a su militancia. Si bien no existió en este partido un menosprecio por el activista universitario, se percibe de la documentación y el bagaje testimonial la existencia de una moral interna que presionaba mayoritariamente a sus miembros a entablar la búsqueda de una inserción laboral y posterior militancia fabril y sindical.

Al mismo tiempo, una de las expresiones más acabadas de la proletarización recayó en una concepción que vislumbró que la inserción del militante en la clase obrera no solamente debía producirse en el marco de un ámbito fabril sino también en el espacio barrial y en la cotidianeidad social. En concordancia con ello, fue frecuente que el militante proletarizado modificara no solo su inserción laboral sino también la ubicación geográfica de su lugar de vivienda para alcanzar una integración completa al espacio obrero. Existen experiencias paradigmáticas en este sentido como, por ejemplo, diversos estudiantes universitarios en los albores de recibirse que abandonaron sus estudios para forjar su ingreso a fábrica, o bien, migrar hacia el interior para posibilitar la apertura política del partido en un espacio no explorado. Cabría aquí el interrogante en torno a la existencia de una cierta tensión interna en la organización para conjugar la labor intelectual del militante con una evidentemente valorada praxis obrerista y sindical. En este sentido, es menester interrogarse si las propias concepciones de esta corriente no se transformaron en un impedimento para un mayor crecimiento y construcción al interior del estudiantado dada la frecuente fuga de cuadros universitarios a la militancia fabril. Como se desprende del siguiente testimonio, la proletarización del estudiante era parte habitual de la práctica partidaria y, como tal, tomada con naturalidad por su militancia:

No estaba la obligación [de proletarizarse] aunque era importante. Los que estábamos en la clase lo mirábamos un poco distinto si demasiado tiempo siendo estudiantes y no saliendo de ahí. Porque la unidad obreroestudiantil era un hecho. Entonces, cómo distinguir lo que representaba una presión de concepción de una realidad que unía a los dos. La clase obrera tenía un conflicto y nosotros lo llevábamos a la universidad, para que griten ahí, hagan colectas, hagan despelote, los estudiantes se solidarizaran. Después había muchas experiencias fallidas de estudiantes que entraban en la fábrica ${ }^{52}$.

Al mismo tiempo, existía la concepción sobre la imposibilidad de desarrollo de un movimiento estudiantil revolucionario sin la existencia, simultáneamente, de un movimiento obrero revolucionario que lo presionara. Sin descartar la posibilidad de una movilización autónoma del estudiantado o de su vanguardia por problemáticas particulares como la

\footnotetext{
${ }^{52}$ Entrevista a Nora Ciapponi realizada por el autor, 15-(09-2012.
} 
Martín Mangiantini, PRT-La Verdad y el movimiento estudiantil argentino. Hacia un análisis de las estrategias de inserción y de las tensiones existentes (1968-1972) / PRT-La Verdad and the argentine student movement. Toward to the analysis of the strategies of insertion and tensions (1968-1972), Revista Izquierdas, $\mathbf{N}^{\circ} 23$, abril 2015, ISSN 0718-5049, IDEA-USACH, pp. 81-101

necesidad de mejorar el presupuesto universitario y frenar las políticas limitacionistas, la lucha por la democracia y el control de las universidades, entre otras, la dirección del PRT LV esgrimía que sólo en combinación con el movimiento obrero, esa lucha tendría consistencia y perdurabilidad ${ }^{53}$.

Un elemento que da cuenta de estas concepciones fue que, incluyo para aquella militancia que se supeditó al ámbito universitario como espacio de participación política, la ligazón con el movimiento obrero era parte fundamental de su cotidianeidad partidaria a través de la participación en conflictos laborales, actividades en las puertas de fábrica, búsqueda de contactos con el proletariado, entre otras variantes habituales ${ }^{54}$. Ello se ejemplifica en el siguiente testimonio que narra la experiencia propia de Buenos Aires:

Acá en Buenos Aires y en La Plata era más sencillo tratar de combinar las dos cosas, incluso intentamos diversas formas organizativas, que la regional universitaria funcionara junto con zonas sindicales de manera tal que las células estudiantiles tuvieran una actividad más o menos sistemática con la actividad en las fábricas, etc. Por ejemplo, era normal que los fines de semana se fueran a vender los periódicos a los barrios obreros e incluso iban los estudiantes también. Era una actividad muy importante. Se insistió con las comisiones obrero-estudiantiles, llevar a estudiantes a participación en las huelgas, etc. Eso era una práctica habitual. Y se retomó con fuerza un criterio que ya existía de antes que es que terminado cada año, una parte importante de los cuadros, salían del trabajo estudiantil e iban hacia el movimiento obrero, se proletarizaban. Siempre fue voluntario, nunca como obligación, más bien en la mayoría de los casos los compañeros querían hacerlo ${ }^{55}$.

Este trabajo tuvo por objetivo comenzar a esbozar una problemática escasamente desarrollada como lo es la relación entre la izquierda orgánica y el movimiento estudiantil en el contexto de radicalización política de los años sesenta y setenta. En este sentido, en las últimas décadas, historiográficamente se experimentan dos fenómenos simultáneos. Por un lado, existe un notorio crecimiento del abordaje sobre las diversas estructuras políticas revolucionarias (o bien, político-militares) existentes en esta coyuntura. Con desigual profundidad, las organizaciones revolucionarias armadas, los partidos trotskistas, las estructuras maoístas y el Partido Comunista han sido estudiados desde distintas producciones. Paralelamente, se produjo un crecimiento no menospreciable de estudios sobre el movimiento estudiantil y de diversos conflictos por éste protagonizados. No obstante, se percibe aún la carencia de una profundización alrededor de la relación que existió entre ambos objetos de estudio. Un abordaje de la izquierda revolucionaria y del

\footnotetext{
${ }^{53}$ "Informe estudiantil", Op. Cit., p. 1.

${ }^{54}$ "La revolución latinoamericana, Argentina y nuestras tareas”. Op. Cit., p. 28.

${ }^{55}$ Entrevista a Aldo Casas realizada por el autor, Buenos Aires, 25-09-2012.
} 
movimiento estudiantil en perspectiva sincrónica se transforma en una temática que merece una mayor profundización dado que es ineludible pensar en ambos actores de modo simultáneo. La izquierda revolucionaria se nutrió del estudiantado en sus filas y buena parte de su crecimiento cuantitativo se explica gracias a este fenómeno y, al mismo tiempo, el movimiento estudiantil estuvo atravesado por las diversas organizaciones revolucionarias actuantes en su seno. El PRT - LV no fue una expresión revolucionaria determinante en el estudiantado en estos años lo cual no supone la ausencia de una cierta participación cuyo análisis posibilita una mayor comprensión del período abierto por el Cordobazo, de la radicalización del estudiantado y del rol jugado en los organismos de masas por las organizaciones revolucionarias existentes en este período.

Recibido: 23 noviembre 2014

Aceptado: 14 enero 2015

\section{BIBLIOGRAFÍA}

- Maximiliano Arecco, "La izquierda obrera y el movimiento estudiantil: la primera intervención del Trotskismo - Morenista en la UBA (1955-1959)”, en Pablo Bonavena y otros, El movimiento estudiantil argentino. Historias con presente (Buenos Aires: Ediciones Cooperativas, 1997), pp. 119-134.

- Pablo Bonavena, "El cuerpo de delegados como forma organizativa del movimiento estudiantil. El doble poder en la Facultad de Filosofía y Letras de la UBA”, en Revista Lucha de Clases (Buenos Aires, 1997).

- Christian Castillo, "El PRT - La Verdad durante 1968 en La Plata, Berisso y Ensenada: Una visión a través de su prensa”. En: Christian Castillo y Marcelo Raimundo, (Compiladores), El 69 platense. Luchas obreras, conflictos estudiantiles y militancia de izquierda en La Plata, Berisso y Ensenada durante la Revolución Argentina (Buenos Aires: Estudios Sociológicos Editora, 2012), pp. 79-109.

- Ernesto González (Comp.), El trotskismo obrero e internacionalista en la Argentina. Tomo 3: Palabra Obrera, el PRT y la Revolución Cubana, Volumen 2 (1963-1969) (Buenos Aires: Editorial Antídoto, 1999).

- Mónica Gordillo, "Protesta, rebelión y movilización: de la resistencia a la lucha armada, 1955-1973”, en Daniel James, Nueva Historia Argentina. Tomo IX: Violencia, proscripción y autoritarismo (1955-1976) (Buenos Aires: Editorial Sudamericana, 2003).

- Martín Mangiantini, El trotskismo y el debate en torno a la lucha armada. Moreno, Santucho y la ruptura del PRT (Buenos Aires: El Topo Blindado, 2014).

- Martín Mangiantini, "Clase y partido. Surgimiento, proletarización y militancia fabril del PRT - La Verdad (1968-1972)", Archivos de Historia del Movimiento Obrero y la Izquierda (Buenos Aires, 2014), pp. 31-52. 
Martín Mangiantini, PRT-La Verdad y el movimiento estudiantil argentino. Hacia un análisis de las estrategias de inserción y de las tensiones existentes (1968-1972) / PRT-La Verdad and the argentine student movement. Toward to the analysis of the strategies of insertion and tensions (1968-1972), Revista Izquierdas, $\mathbf{N}^{\circ} 23$, abril 2015, ISSN 0718-5049, IDEA-USACH, pp. 81-101

- Diego Martínez, El trotskismo morenista en la UBA (1969-1973), Ponencia, Jornadas de Sociología UBA (Buenos Aires, 2012).

- Nahuel Moreno, Argentina y Bolivia: Un balance, (Buenos Aires: Pluma, 1973).

- Nahuel Moreno, Un documento escandaloso (En respuesta a 'En defensa del leninismo, en defensa de la Cuarta Internacional' de Ernest Germain) (Buenos Aires: Ediciones Antídoto, 1989).

- Oscar Terán, Nuestros años sesenta. La formación de la nueva izquierda intelectual argentina, 1956-1966 (Buenos Aires: Puntosur, 1991). 